\title{
The Relationship between Morphology of Sella Turcica and Skeletal Class III Malocclusion in RSGMP FKG USU
}

\author{
Fitri Wardani \\ Faculty of Dentistry, University Sumatera Utara \\ Medan, Indonesia \\ Fiwa79@yahoo.com
}

\author{
Erna Sulistyawati \\ Department of Orthodontic \\ Faculty of Dentistry, University Sumatera Utara \\ Medan, Indonesia
}

\author{
Muslim Yusuf \\ Department of Orthodontic \\ Faculty of Dentistry, University Sumatera Utara \\ Medan, Indonesia
}

\begin{abstract}
The sella turcica is one of the commonly used orthodontic landmarks in determining and diagnosing various problems of the facial skeleton.The pituitary gland is located in the sella turcica. Thus, various pathologies of this gland and developmental disorder of frontonasal and maxilla can change the morphology of sella turcica. The purpose of this study was to determine relationship between the morphology of sella turcica and skeletal Class III malocclusion in RSGMP FKG USU Medan, Indonesia. The samples in this study were 104 lateral cephalogram with aged range from 17-35 years old and were divided into two groups. First group consists of 52 lateral cephalogram with skeletal Class I malocclusion and the second group consists of 52 lateral cephalogram with skeletal Class III malocclusion. The morphology of sella turcica was analyzed based on theory Axelsson et al. Results showed that the sella turcica with normal morphology found greater in skeletal Class I malocclusion group $(67,3 \%)$ compared to the second group with skeletal Class III malocclusion $(17,3 \%)$. Bridging of the sella turcica was found greater in skeletal Class III malocclusion (30.8\% of the subjects) than the skeletal Class I malocclusion (13.5 \%). As conclusion, there was a significant difference between morphology of sella turcica between the skeletal Class III malocclusion and skeletal Class I malocclusion. There was also relationship between morphology of sella turcica and skeletal Class III malocclusion.
\end{abstract}

Keywords-morphology of sella turcica, bridging of sella turcica, class III skeletal malocclusion

\section{INTRODUCTION}

Sella turcica has an important role in the orthodontic. The structure of Sella turcica used in neurocranial analysis and craniofacial complex. Sella turcica is a significant anatomical structure in the measurement of lateral cephalometry. In the analysis of dentofacial cephalometry and neurocranial morphology, the sella point which central landmark located in the middle of sella turcica is an important reference used for the evaluation of craniofacial morphology, the relationship of the intermaxillary to the cranium and the cephalometric serial superimposition [1-7].

Sella turcica is a saddle-shaped base on sphenoid bone located in the center of the cranial fossa located on the intracranial surface of the skull. This saddle-shaped curve is known as the pituitary fossa or the pituitary fossa. The pituitary gland is in the pituitary fossa, limited to the anterior portion by the sella tubercullum and posteriorly by dorsum sella $[3,5,10]$.

The development of sella turcica is closely related to the development of the pituitary gland. The pituitary gland is located in sella turcica so that pathological conditions in these glands can cause changes in the shape or morphology and size of the sella turcica. The development of pituitary gland has been complete before the completion of the development of sella turcica [6].

The abnormalities or pathological conditions in the pituitary gland may manifest in morphology of sella turcica due to regulatory disorders of glandular secretion of hormones, prolactin, growth hormone, follicular stimulating hormone and others. Malformations in the cells or pituitary gland may be associated with growth malformations in the craniofacial region (frontonasal, maxilla, palatal and mandibular) sometimes involving the brainstem, thymus, thyroid and velocardiofacial syndrome [7]

The morphological assessment of sella turcica can be an indicator in assuring or assessing the pituitary gland. Morphological variations of sella turcica were reported in cases with severe craniofacial deviation, genetic abnormalities, syndrome abnormalities as well as dental anomalies. Many researchers report that the prevalence of morphology of sella turcica such as the presence of bridging is more common in subjects with dental anomalies, cleft lip and palate and other anomalious variations $[9,12]$. 
Fusion of the anterior and posterior processus clinoideus which also called bridging sella turcica (STB). Cederberg et al. 2003, Axelsson et al 2004, Jones et al. 2005, found that the incidence of bridging on healthy subjects ranged from 3.8 to $13 \%$ [8]. Abdel Kader 2007, statistically stated that the incidence of bridging sella turcica is more common in Class III malocclusions than in Class I and Class II malocclusions [4].

Orthodontists should be familiar with the various morphologic of sella turcica that will assist in the diagnosis of pathological disorders associated with it [1,3]. Friedland and Meazzini state by knowing the normal anatomy of radiographs and morphological variations of sella turcica so we will be able to recognize and search know deviations that indicate a skeletal discrepancy even before the condition is seen clinically $[2,20]$.

\section{MATERIALS AND METHODS}

This research is an observational research with cross sectional method. The research population was taken from patients at Orthodontic Clinic of Dental Hospital and Mouth Education of Faculty of Dentistry, University Sumatera Utara (RSGMP FKG USU) with age range 17-35 years. The samples were a lateral cephalometric photograph of the patient with Class I and III skeletal malocclusion. Based on the large sample calculation with 1:1 proportion, the minimum sample for each group were 52 samples, so the total samples were 104 samples. Only the radiographs which showed the clear image were selected for interpretation and analysis.

Radiographs were divided into different classes based on ANB angle value of SNA and SNB, which Class I: ANB angle $\pm 2^{\circ}$ and Class III: ANB Angle < 0o. Facial skeletal types were based on the anteroposterior relationship of the maxilla and the mandible (Class I, II and III). These three types are explained by ANB angle based on Steiner analysis.

The sella turcica region was traced on each cephalometric radiograph on thin acetate paper under ideal lighting. Then, different parts of the sella turcica including tuberculum sella, dorsum sella, anterior and posterior clinoid processes were all traced. Identification of morphology of sella turcica was in accordance with Axelsson et al. The recent study by Axelsson in 2004, the morphology of sella turcica were divided into six types: normal sella turcica, oblique anterior wall, double contour of the floor, bridging, irregularity in the posterior, pyramidal shape of the dorsum sella (Figure 1).

Methods analysis of the study using SPSS program, the data will be analyzed descriptively to see the frequency distribution based on the characteristic of the research sample. The numerical data will be presented in terms of average and standard deviation. To assess the relationship between the morphology of sella turcica and the type of skeletal Class III malocclusion, a Somers test was conducted and to assess the morphological difference between the subjects and the control group used Chi Square test.

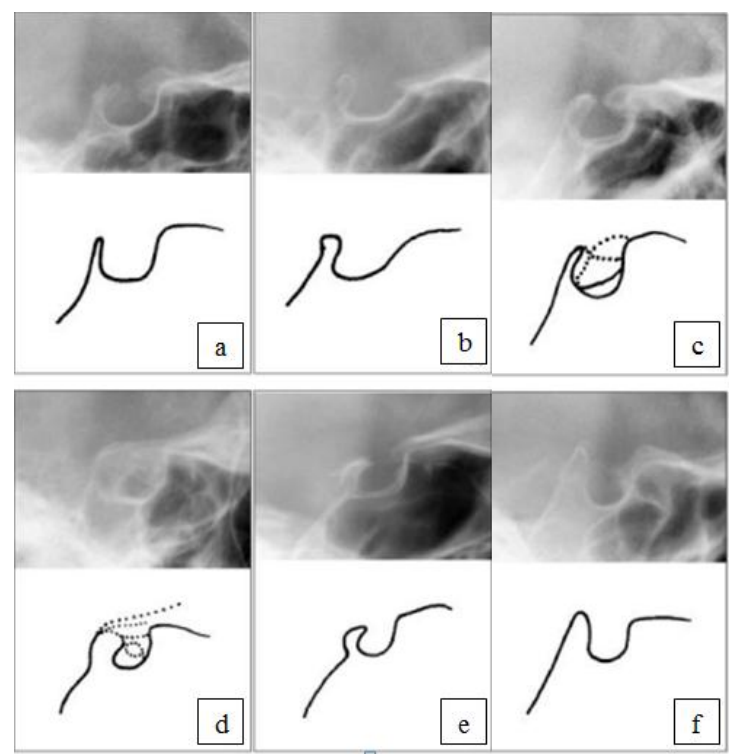

Figure 1. Types of morphology of sella turcica: (a) normal sella turcica, (b) oblique anterior wall, (c) double contour of the floor, (d) bridging, (e) irregularity in the posterior, (f) pyramidal shape of the dorsum sella (Axelsson et all 2004) $[6,7,10,16]$

\section{RESULTS}

Results of this study shows that normal morphology of sella turcica mostly found in the sample group of Class I skeletal as many as 35 samples or $67.3 \%$. The second highest found of morphological variation sella turcica was bridging for 7 samples $(13.5 \%$ ) (Table I).

TABLE I. DISTRIBUSION OF SELLA TURCICA MORPHOLOGY IN SKELETAL CLASS I MALOCCLUSION

\begin{tabular}{|l|c|c|}
\hline \multicolumn{1}{|c|}{ Morphology } & $\mathbf{n}$ & Class I (n=52) \\
\hline Normal & 35 & $67.3 \%$ \\
\hline Oblique anterior wall & 2 & $3.8 \%$ \\
\hline Double contour of the floor & 1 & $1.9 \%$ \\
\hline Bridging & 7 & $13.5 \%$ \\
\hline Irregularity in the posterior part & 4 & $7.7 \%$ \\
\hline Pyramidal of dorsum sella & 3 & $5.8 \%$ \\
\hline
\end{tabular}

The results of this study shown that the morphology of sella turcica in the skeletal class III malocclusion group is mostly found was the presence of bridging, 16 samples $(30.8 \%)$ compared to the normal morphology of sella turcica which only 9 samples (17.3\%). Furthermore, the second most variation morphology of sella turcica on Skeletal Class III malocclusion was irregularity in the posterior part which 13 samples (25\%) (Table II).

TABLE II. DISTRIBUTION OF SELLA TURCICA MORPHOLOGY IN CLASS III SKELETAL MALOCCLUSION

\begin{tabular}{|l|c|c|}
\hline \multicolumn{1}{|c|}{ Morphology } & N & Class III (n=52) \\
\hline Normal & 9 & $17.3 \%$ \\
\hline Oblique anterior wall & 5 & $9.6 \%$ \\
\hline Double contour of the floor & 5 & $9.6 \%$ \\
\hline Bridging & 16 & $30.8 \%$ \\
\hline Irregularity in the posterior part & 13 & $25.0 \%$ \\
\hline Pyramidal of dorsum sella & 4 & $7.7 \%$ \\
\hline
\end{tabular}


Table III shows a significant difference between the morphology of sella turcica in the skeletal Class I malocclusion group compared with the skeletal Class III malocclusion group where the normal morphology is more common in the skeletal Class I malocclusion group of $79.5 \%$. The morphological variation of sella tursika was more common in the skeletal Class III malocclusion group than in the Class I malocclusion group of 43 samples or $71.7 \%$.

TABLE III. MORPHOLOGICAL DIFFERENCE OF SELLA TURCICA IN SKELETAL CLASS I AND SKELETAL CLASS III MALOCCLUSION

\begin{tabular}{|l|c|c|c|c|c|}
\hline \multicolumn{1}{|c|}{$\begin{array}{c}\text { Morphology of sella } \\
\text { turcica }\end{array}$} & \multicolumn{2}{|c|}{$\begin{array}{c}\text { Class I } \\
(\mathbf{n = 5 2})\end{array}$} & $\begin{array}{c}\text { Class III } \\
(\mathbf{n = 5 2})\end{array}$ & P \\
\hline Normal & 35 & $79.5 \%$ & 9 & $20.5 \%$ & $0.0001^{*}$ \\
\hline Morphology of Sella Turcica & 17 & $28.3 \%$ & 43 & $71.7 \%$ & $0.0001 *$ \\
\hline
\end{tabular}

Table IV shows a significant difference in morphological variation of sella turcica in the skeletal Class I malocclusion group compared with the skeletal Class III malocclusion group. The normal morphology of sella tursika is mostly found in the group of skeletal Class I that is 35 samples $(79.5 \%)$ while in the sample skeletal Class III group were 9 sample (20.5\%). The most frequent morphological variation of sella turcica in skeletal Class III malocclusion group was bridging as many as 16 samples $(69.6 \%)$ while in sample group of Class I skeletal were 7 sample (30.4\%).

TABLE IV. DIFFERENCES IN MORPHOLOGICAL VARIATION OF SELLA TURCICA IN SKELETAL CLASS I AND SKELETAL CLASS III MALOCCLUSION

\begin{tabular}{|l|c|c|c|c|c|c|}
\hline $\begin{array}{c}\text { Malocclu- } \\
\text { sion }\end{array}$ & $\begin{array}{c}\text { Obli- } \\
\text { que }\end{array}$ & $\begin{array}{c}\text { Double } \\
\text { contour }\end{array}$ & Bridging & $\begin{array}{c}\text { Irregu- } \\
\text { larity }\end{array}$ & $\begin{array}{c}\text { Pyra- } \\
\text { midal }\end{array}$ & p \\
\hline Class I & 2 & 1 & 7 & 4 & 3 & 0.0001 \\
& $(28.6 \%)$ & $(16.7 \%)$ & $(30.4 \%)$ & $(23.5 \%)$ & $(76.5 \%)$ & \\
\hline Class III & 5 & 5 & 16 & 13 & 4 & 0.0001 \\
& $(71.4 \%)$ & $(83.3 \%)$ & $(69.6 \%)$ & $(42.9 \%)$ & $(57.1 \%)$ & \multicolumn{5}{|c|}{ *Chi Square test } \\
\hline
\end{tabular}

The results of this study indicate that there is a correlation between skeletal Class III malocclusion with morphological variation of sella turcica. Table $\mathrm{V}$ shows the results of Somers test there is a negative correlation between skeletal Class III malocclusion with morphology variation of sella turcica with correlation coefficient value $(r)=-0.506$ which means that the smaller the ANB value, the highest variation morphology of sella turcica.

TABLE V. CORRELATION BETWEEN MORPHOLOGICAL VARIATIONS OF SELLA TURCICA WITH SKELETAL CLASS III MALOCCLUSION BASED ON SOMERS TEST

\begin{tabular}{|l|c|c|c|}
\hline \multicolumn{1}{|c|}{ Correlation between variable } & N & R & P \\
\hline $\begin{array}{l}\text { Morphological variation of sella } \\
\text { turcica with skeletal class III } \\
\text { malocclusion }\end{array}$ & 104 & -0506 & 00001 \\
\hline
\end{tabular}

\section{DISCUSSION}

Based on the research of Solmaz et al in Iranian subject, the normal morphology of sella turcica was $24.4 \%$ and $75.6 \%$ have morphological variation of sella turcica. Alkofide in his study was evaluating the morphology and size of sella turcica in patients with skeletal classification Class I, Class II and Class III. He reported that the normal morphology of sella turcica was $67 \%$ of cases; the remaining $33 \%$ had variations in morphology of sella turcica. Research by Mahmood Shah, the normal morphology was $66 \%$ of subjects [6]. In this study the most normally morphology of sella turcica was obtained in the first group of skeletal class samples of 35 samples $(79.5 \%)$ while in the Skeletal Class III sample group only 9 sample $(20.5 \%)$.

The fusion of the anterior and posterior processus clinoideus is called bridging sella turcica (STB). Cederberg et al. 2003, Axelsson et al 2004, Jones et al 2005 , stated that the incidence of bridging on healthy subjects ranged from 3.8 to $13 \%$ [8]. Abdel Kader 2007, statistically incidents of bridging sella turcica were more common in Class III malocclusions than in malocclusions Class I and Class II [4]. In accordance with this research, morphology variation of sella turcica most commonly found in skeletal class III malocclusion group is bridging as many as 16 samples (69.6\%) whereas in sample group of Class I skeletal only found 7 samples $(30.4 \%)$. The second majority of morphology variation of sella turcica on skeletal class III malocclusion is irregularity in the posterior part of 13 samples $(76.5 \%)$ whereas in skeletal Class 1 malocclusion is 4 samples $(23.5 \%)$.

The presence of congenital malformations in brain development can be detected by analyzing neurocranium. The abnormal morphology of cranial base and sella turcica is included in the evaluation of postnatal craniofacial malformations $[1,7,17]$. In accordance with the results of this study indicating a significant difference in morphological variation of sella turcica in the skeletal Class I malocclusion group compared with the skeletal Class III malocclusion group. Normal morphology of sella turcica was highest in the first group of skeletal Class I samples with ANB $0^{\circ}-4^{\circ}$ as much as 35 samples $(79.5 \%)$ compared to the Skeletal Class III samples group with ANB $-8^{\circ}$ to $-1^{\circ}$ values of 9 samples $(20.5 \%)$, wherein we know that the ANB angle represents a discrepancy of sagittal growth from the apical base of the jaw.

As the conclusion, the results of this study may be useful in diagnosis and treatment plan by knowing and considering the normal anatomy radiographs of sella turcica and variations morphology of sella turcica so we will be able to recognize some deviations that indicate a skeletal discrepancy even before the condition is seen clinically, so that the orthodontist can determine the right time to perform orthopedic functional treatment.

\section{REFERENCES}

[1] B. Ali, A. Shaikh, M. Fida, "Association between sella turcica bridging and palatal canine impaction," Am. J. Orthod Dentofacial Orthop., vol. 146, pp. 437-41, 2014

[2] S. Axelsson, K. Storhaug, I. Kjaer, "Post-natal size and morphology of the sella turcica. Longitudinal cephalometric standards for norwegians between 6 and 21 years of age," European Journal of Orthodontics, vol. 26, pp. 597-604, . 2004. 
[3] P. Meyer-Marcotty, T. Reuther, A. Stellzig-Eisenhauer, "Bridging of the sella turcica in skeletal class III subjects," European Journal of Orthodontics, vol. 32, pp. 148-153, 2009.

[4] J.P. Becktor, S. Einersen, I. Kjaer, "A sella turcica bridge in subjects with severe craniofacial deviations," European Journal of Orthodontics, vol. 22, pp. 69-74, 2000.

[5] R.M. Jones, A. Faqir, D.T Millett, "Bridging and dimensions of sella turcica in subjects treated by surgical-orthodontic means or orthodontics only," Angle Orthod., vol. 75, pp. 714-718, 2005.

[6] S. Valizadeh, S. Shahrzad, S. Mohseni, "Correlation of shape and size of sella turcica with the type of facial skeletal class in Iranian group," Iran J. Radiol., vol. 3, pp.1-7, 2015.

[7] H.P. Sathyanarayana, V. Kailasam, A.B. Chitharanjan, "Sella turcica - Its importance in orthodontics and craniofacial morphology," vol. 10(5), pp. 571-575, 2013.

[8] R. Leonardi, E. Barbato, M. Vichi, "A sella turcica bridge in subjects with dental anomalies," European Journal of Orthodontics, vol. 28, pp. 580-585, 2006.

[9] G.S. Ani, J. Jose, S.P. Prasanth, "Morphology of sella turcica in subjects with highly placed canines," Int. J. Bioassays, vol. 4(6), pp. 3968-3972, 2015.

[10] T. Nagaraj, R. Shruthi, L. James, "The size and morphology of sella turcica: A lateral cephalometric study," Journal of Medicine, Radiology, Pathology \& Surgery, vol. 1, pp. 3-7, 2015.

[11] A. Kucia, T. Jankowski, M. Siewniak, "Sella turcica anomalies on lateral cephalometric radiographs of polish children," Dentomaxillofacial Radiology, vol. 43, pp. 1-6, 2014.

[12] I.E. Perez, A.K. Chavez, D. Ponce, "Frequency of sela turcica bridge and clinoid enlargement in lateral cephalometric plain film radiography from peruvians," Int. J. Morphol., vol. 31(2), pp. 373-377, 2013
[13] A. Becker, S. Chaushu, "Etiology of maxillary canine impaction: A review," Am. J. Orthod. Dentofacial Orthop., vol. 148 , pp. 557-67, 2015

[14] I. Kjaer, "Sella turcica morphology and the pituitary gland- a new contribution to craniofacial diagnostics based on histology and neuroradiology," European Journal of Orthodontics, vol. 37(1), pp. 28-35, 2015

[15] R. Leonardi, M. Farella, M.T. Cobourne, "An association between sella turcica bridging and dental transposition," European Journal of Orthodontics, vol. 33, pp. 461-465, 2011.

[16] S.A. Mahmood, U. Bashir, "The shape and size of the sella turcica in skeletal class I, II \& III in patients presenting at Islamic International Dental Hospital, Islamabad," Pakistan Ora \& Dental Journal, vol. 31(1), pp. 104-110, 2011.

[17] G.S. Ani, J. James, S.P. Prasanth, "Morphology of sella turcica in skeletal class II subjects medical sciences - Faculty of Dentistry," vol. 4, pp. 1-12, 2014.

[18] I.N. Ize-Iyamu, "Sella turcica shape, linear dimensions and cervikal vertebrae staging in preorthodontic patients in Benin City, Nigeria," Sahel Medical Journal, vol. 17(4), pp. 151-158, 2014.

[19] A.R.P. Kusuma, "Bernafas lewat mulut sebagai faktor ekstrinsik etiologi maloklusi," Majalah Ilmiah Sultan Agung, vol. 48(123), pp. $1-19,2010$

[20] M. Andredaki, A. Koumantanou, A. Dorotheou, "A cephalometric morphometric study of sella turcica," European Journal of Orthodontics, vol. 29, pp. 449-456, 2007.

[21] G. Singh, Textbook of orthodontics, $2^{\text {nd }}$ ed., New Delhi: Jaypee, 2007, pp. 3-6, 30-6, 94-116.

[22] A. Jacobson, Radiographic cephalometry: From basics to videoimaging. London: Quintessence Publishing Co, 1995, pp. $77-79$. 